\title{
Article
}

\section{Effects of a 10 week footstrike transition in habitual rearfoot runners with patellofemoral pain}

Sinclair, Jonathan Kenneth

Available at http://clok.uclan.ac.uk/15382/

Sinclair, Jonathan Kenneth ORCID: 0000-0002-2231-3732 (2016) Effects of a 10 week footstrike transition in habitual rearfoot runners with patellofemoral pain. Comparative Exercise Physiology, 12 (3). pp. 141-150. ISSN 1755-2540

It is advisable to refer to the publisher's version if you intend to cite from the work. http://dx.doi.org/10.3920/CEP160013

For more information about UCLan's research in this area go to http://www.uclan.ac.uk/researchgroups/ and search for < name of research Group>.

For information about Research generally at UCLan please go to http://www.uclan.ac.uk/research/

All outputs in CLoK are protected by Intellectual Property Rights law, including Copyright law. Copyright, IPR and Moral Rights for the works on this site are retained by the individual authors and/or other copyright owners. Terms and conditions for use of this material are defined in the policies page.

\section{CLoK}

Central Lancashire online Knowledge www.clok.uclan.ac.uk 


\section{Comparative Exercise Physiology}

\section{Effects of a 10 week footstrike transition in habitual rearfoot runners with patellofemoral pain. \\ --Manuscript Draft--}

\begin{tabular}{|c|c|}
\hline Manuscript Number: & CEP-160013 \\
\hline Keywords: & Biomechanics, knee, footstrike, running. \\
\hline \multicolumn{2}{|l|}{$\begin{array}{l}\text { Corresponding Author Secondary } \\
\text { Information: }\end{array}$} \\
\hline Corresponding Author's Institution: & University of Central Lancashire \\
\hline \multicolumn{2}{|l|}{ First Author Secondary Information: } \\
\hline Order of Authors: & Jonathan Sinclair, PhD, BSc (Hons) \\
\hline \multicolumn{2}{|c|}{ Order of Authors Secondary Information: } \\
\hline Abstract: &  \\
\hline
\end{tabular}


1

2

\section{Correspondence Address:}

7 Dr. Jonathan Sinclair,

8 Centre for Applied Sport Exercise and Nutritional Sciences

9 School of Sport and Wellbeing,

10 College of Health and Wellbeing,

11 University of Central Lancashire,

12 Preston

13

14

15

16

17 Keywords: Biomechanics, knee, footstrike, running.

18

19

20

21

patellofemoral pain.

\section{Jonathan Kenneth Sinclair ${ }^{1}$}

1. Centre for Applied Sport and Exercise Sciences, School of Sport and

Wellbeing, College of Health and Wellbeing, University of Central Lancashire.

Lancashire

PR1 2HE.

e-mail: jksinclair@uclan.ac.uk

19 Abstract

Patellofemoral pain is the most common pathology in runners. Mid/fore foot runners experience lower patellofemoral loading compared to those who use a rearfoot strike. The aim of this study was to examine the efficacy of a 10-week intervention allowing runners with patellofemoral pain to transition from a rearfoot strike pattern. Nine male runners with patellofemoral pain were given a graduated 10-week program which 
allowed them to convert their habitual rearfoot strike pattern. Lower extremity kinematics, tibial accelerations, loading rates, patellofemoral kinetics and Achilles tendon kinetics were collected. Self-reported knee and Achilles tendon pain were examined using the Knee injury and Osteoarthritis Outcome Score and numeric pain rating scale. Data were collected before and after the 10-week transition. Reductions were found in peak patellofemoral force/ pressure (pre transition $=4.76 \mathrm{BW} \&$ 13.10MPa \& post transition $=4.27 \mathrm{BW} \& 11.48 \mathrm{MPa}$ ). Improvements were shown for Knee injury and Osteoarthritis Outcome Score subscales pain (pre transition $=62.04$ $\&$ post transition $=78.41)$, sport $($ pre transition $=53.61 \&$ post transition $=72.67)$, function and daily living (pre transition $=67.68 \&$ post transition $=80.08$ ). Increases were however found for peak Achilles tendon force (pre transition $=5.07 \mathrm{BW} \&$ post transition $=5.58 \mathrm{BW}$ ) and Achilles tendon pain (pre transition $=1.06 \&$ post transition = 2.67). Transitioning from a rearfoot strike pattern reduces patellofemoral loading and pain symptoms. The key implication is that rearfoot strike runners with patellofemoral pain can reduce their pain symptoms by altering their footstrike pattern; although this may be at the expense of increased pain at the Achilles tendon.

\section{Introduction}

Runners are regarded as being highly susceptible to chronic pathologies (Taunton et al., 2003), with an incidence of 19.4-79.3\% over the course of one year (Van Gent et al., 2007). Patellofemoral pain syndrome has been shown to be the most common chronic pathology in runners (Ahn et al., 2014).

Patellofemoral pain syndrome presents as pain in the posterior aspect of the patella mediated through overuse and excessive loading of the patellofemoral joint itself 
50 during cyclical dynamic activities such as running (Besier et al., 2005). Pain associated with patellofemoral disorders can be debilitating and can severely restrict runners' ability to train (Witvrouw et al., 2013). Patellofemoral pain symptoms are difficult to treat and can persist for many years (Nimon et al., 1998). It has been shown that between $45-64 \%$ of those who exhibit pain symptoms later present with radiographic evidence of osteoarthritis at the patellofemoral joint (Crosslet, 2014).

The concept of footstrike patterns in runners has received considerable attention in biomechanics literature (Liebermann et al., 2010). Runners are categorized into one of three footstrike classifications; rearfoot strikers (RF), midfoot strikers (MF), and forefoot strikers (FF) on the basis of their foot position at the instant of initial ground contact (Kulmala et al., 2013). Around $80 \%$ of runners utilize a RF strike pattern (Williams et al., 2000), because MF and FF strike runners are a minority they are typically grouped together and termed FF (Ahn et al., 2014). FF strike runners utilize a shorter stride length and an enhanced stride frequency which serve to reduce the duration over which the stance phase occurs (Divert et al., 2008; Sinclair et al., 2013; Squadrone \& Gallozzi, 2009). Alterations in stride length/ frequency also facilitate mechanical alterations in lower extremity alignment; FF strike runners utilize increased plantarflexion of the ankle joint and flexion of the knee joint at the instance of footstrike (Kulmala et al., 2013; Sinclair et al., 2013; Squadrone \& Gallozzi, 2009; Sinclair, 2014).

Biomechanical research has contrasted the running mechanics of those who utilize rearfoot and non-rearfoot strike patterns. Liebermann et al., (2010) and Cavanagh \& Lafortune (1980) contrasted vertical ground reaction force parameters between RF 
and FF strike runners. Their findings showed that FF strike running was characterized by the absence of an impact peak and also a reduction in the loading rate of the vertical ground reaction force. Hamill et al., (2014) contrasted knee and ankle joint stiffness characteristics in RF and FF strike runners. Their findings indicated that FF runners exhibited increased knee stiffness and decreased ankle stiffness in relation to RF strike runners. Kulmala et al., (2013) examined differences in patellofemoral and Achilles tendon kinetics between RF and FF strike runners. Their observations showed that rearfoot strike runners were associated with significantly larger patellofemoral kinetics whereas forefoot strike runners exhibited significantly greater Achilles tendon loads.

The observations of Kulmala et al., (2013), lead to the notion that FF strike runners may be associated with a reduced susceptibility to patellofemoral pain in relation to those who adopt a RF pattern. This conjecture is supported by the findings of the retrospective study conducted by Daoud et al., (2012) which demonstrated that FF strike runners are twofold less likely to suffer from a chronic knee pathology in comparison to RF strikers. Although most runners have a habitual and autonomous landing strategy, recent evidence has shown that RF strike runners can convert their running pattern to a FF technique (Williams et al., 2000; Moore et al., 2015).

Therefore, the aim of the current investigation was to investigate the efficacy of a 10 week intervention which allowed runners to transition from a RF to a FF footstrike pattern in runners with patellofemoral pain. Research of this nature may improve understanding of conservative management of patellofemoral pain and also provide 
runners with a key treatment mechanism. The current study tests the hypothesis that following the 10-week intervention runners pain symptoms will improve.

\section{Methods}

\section{Participants}

Nine male recreational runners volunteered to take part in this study. The mean characteristics of the participants were: age $29.33 \pm 4.21$ years, height $1.72 \pm 0.11 \mathrm{~m}$ and body mass $69.11 \pm 5.66 \mathrm{~kg}$. Each runner initially exhibited a RF strike pattern which was verified by the presence of an impact peak in their vertical ground reaction force curve (Cavanagh \& Lafortune, 1980) and also through individual examination of participant's sagittal plane ankle positions at foot strike (Sinclair et al., 2015). Participants were included into the study only if they showed symptoms of patellofemoral pain and no evidence of any other pathology. Patellofemoral pain diagnosis was made as a function of the clinical presentation of symptoms in accordance with the recommendations of Crossley et al., (2002). Participants provided written informed consent in accordance with the principles outlined in the Declaration of Helsinki. The procedure utilized for this investigation was approved by the University of Central Lancashire, Science, Technology, Engineering and Mathematics, ethical committee REF 381.

\section{Transition programme}

Following initial data collection each participant was given a structured programme of running using a FF strike pattern and exercises designed to reduce the likelihood of injury (Table 1). Instructions for changes in running technique were provided taking into account and adapting where appropriate previous observations from 
124 biomechanics literature. Specifically, participants were instructed to 1. Increase their 125 cadence and to decrease their stride length (Liebermann et al., 2010; Warne et al., 126 2014), 2. Run with light footfalls, landing on the ball of the foot (Warne et al., 2014; 127 Crowell et al., 2011), and 3. Keep the head up and run as tall as possible 128 (Liebermann et al., 2010; Warne et al., 2014). The program allowed runners to 129 continue their normal training load but increased the proportion of total mileage in 130 which a FF strike pattern was used by $10 \%$ each week, thus exposure FF strike 131 running was gradually increased (Moore et al., 2015; Warne et al., 2014). Four 132 strengthening exercises and four stretching exercises were provided to participants in 133 order to prevent injury during the transition (Warne et al., 2014); these were also 134 introduced in a graduated manner. 


\section{Procedure}

Participants were required to report to the laboratory on two occasions. On their initial visit to the laboratory they were required to complete ten running trials at 4.0 $\mathrm{m} / \mathrm{s}$. Running velocity was monitored using infra-red timing gates (SmartSpeed Ltd, Cardiff, UK) and a maximum deviation of $5 \%$ was allowed. The stance phase of the running cycle was delineated as the time over which a minimum of $20 \mathrm{~N}$ vertical force was applied to the force platform. Participants also completed the Knee injury and Osteoarthritis Outcome Score (KOOS) questionnaire in order to obtain a baseline measure of their knee pain. Finally, because FF strike running has been shown to increase the loads borne by the Achilles tendon (Kulmala et al., 2013), participants were also asked to rate their Achilles tendon pain using the numeric pain rating scale (NPS). Following the 10 week intervention participants returned to the laboratory where the protocol was repeated. Participants wore laboratory footwear for their data collection (New Balance 1260 v2), in sizes 7-11 UK).

Kinematic information from the lower extremity joints was obtained using an eight camera motion capture system (Qualisys Medical AB, Goteburg, Sweden) using a capture frequency of $250 \mathrm{~Hz}$. Dynamic calibration of the system was performed before each data collection session. Calibrations producing residuals $<0.85 \mathrm{~mm}$ and points above 4000 in all cameras were considered acceptable. To measure kinetic information an embedded piezoelectric force platform (Kistler National Instruments, Model $9281 \mathrm{CA}$ ) operating at $1000 \mathrm{~Hz}$ was utilized. The kinetic and kinematic information were synchronously obtained and interfaced using Qualisys track manager. 
To quantify lower extremity kinematics, the calibrated anatomical systems technique was utilized (Cappozzo et al., 1995). Retroreflective markers (19 mm) were positioned unilaterally allowing the; foot, shank and thigh to be defined. The foot was defined via the 1st and 5th metatarsal heads, medial and lateral malleoli and tracked using the calcaneus, 1st metatarsal and 5th metatarsal heads. The shank was defined via the medial and lateral malleoli and medial and lateral femoral epicondyles and tracked using a cluster positioned onto the shank. The thigh was defined via the medial and lateral femoral epicondyles and the hip joint centre and tracked using a cluster positioned onto the thigh. To define the pelvis additional markers were positioned onto the anterior (ASIS) and posterior (PSIS) superior iliac spines and this segment was tracked using the same markers. The centers of the ankle and knee joints were delineated as the mid-point between the malleoli and femoral epicondyle markers (Graydon et al., 2015; Sinclair et al., 2015). The hip joint centre was determined using a regression equation that uses the positions of the ASIS markers (Sinclair et al., 2014). Each tracking cluster comprised four retroreflective markers mounted onto a thin sheath of lightweight carbon-fibre. Static calibration trials were obtained allowing for the anatomical markers to be referenced in relation to the tracking markers/ clusters. The $\mathbf{Z}$ (transverse) axis was oriented vertically from the distal segment end to the proximal segment end. The $\mathrm{Y}$ (coronal) axis was oriented in the segment from posterior to anterior. Finally, the $\mathrm{X}$ (sagittal) axis orientation was determined using the right hand rule and was oriented from medial to lateral.

To measure axial accelerations at the tibia an accelerometer (Biometrics ACL 300, Gwent United Kingdom) sampling at $1000 \mathrm{~Hz}$ was used. The accelerometer was attached onto a piece of lightweight carbon-fibre material using the protocol outlined 
by Sinclair et al., (2013). The tibial accelerometer was strapped securely to the distal anterio-medial aspect of the tibia in alignment with its longitudinal axis $0.08 \mathrm{~m}$ above the medial malleolus (Sinclair et al., 2010). Strong non-stretch adhesive tape was placed over the device and leg to avoid overestimating the acceleration due to tissue artefact.

\section{Processing}

Dynamic trials were processed using Qualisys Track Manager and then exported as C3D files. Ground reaction force (GRF) and marker data were filtered at $50 \mathrm{~Hz}$ and $15 \mathrm{~Hz}$ respectively using a low-pass Butterworth 4th order filter and processed using Visual 3-D (C-Motion, Germantown, MD, USA). Joint kinetics were computed using Newton-Euler inverse-dynamics, allowing net knee joint moments to be calculated. Angular kinematics of the lower extremity joints were calculated using an $X Y Z$ (sagittal, coronal and transverse) sequence of rotations. To quantify joint moments segment mass, segment length, GRF and angular kinematics were utilized using the procedure previously described by Sinclair, (2014). Discrete lower extremity joint kinematic measures were extracted for statistical analysis were 1) angle at footstrike, 2) peak angle and 3) relative range of motion (representing the angular displacement from footstrike to peak angle).

Patellofemoral loading was examined through extraction of peak patellofemoral contact force and peak patellofemoral contact pressure. Patellofemoral contact force during running was estimated using knee flexion angle (kf) and knee extensor moment (KEM) through the biomechanical model of Ho et al., (2012). This model has been utilized previously to resolve differences in patellofemoral contact force and 
pressure in different footwear and footstrike patterns (Besier et al., 2005; Kulmala et al., 2013; Sinclair, 2014), and between those with and without patellofemoral pain (Keino et al., 2002).

The effective moment arm distance $(m)$ of the quadriceps muscle (QM) was calculated as a function of $\mathrm{kf}$ using a non-linear equation, based on information presented by van Eijden et al., (1986).

$$
\mathrm{QM}=0.00008 \mathrm{kf}^{3}-0.013 \mathrm{kf}{ }^{2}+0.28 \mathrm{kf}+0.046
$$

The force of the quadriceps (FQ) was calculated using the below formula:

$$
\mathrm{FQ}=\mathrm{KEM} / \mathrm{QM}
$$

Net patellofemoral contact force was estimated using the FQ and a constant $(\mathrm{C})$ :

$$
\text { patellofemoral contact force }=\mathrm{FQ}{ }^{*} \mathrm{C}
$$

The $\mathrm{C}$ was described in relation to $\mathrm{kf}$ using a curve fitting technique based on the non-linear equation described by van Eijden et al., (1986):

$$
\begin{gathered}
C=\left(0.462+0.00147{ }^{*} \mathrm{kf}^{2}-0.0000384{ }^{*} \mathrm{kf}^{2}\right) /\left(1-0.0162{ }^{*} \mathrm{kf}+0.000155^{*} \mathrm{kf}^{2}-\right. \\
\left.0.000000698{ }^{*} \mathrm{kf}^{3}\right)
\end{gathered}
$$

Patellofemoral contact pressure (MPa) was calculated using the net patellofemoral contact force divided by the patellofemoral contact area. The contact area was 
described using the $\mathrm{Ho}$ et al., (2012) recommendations by fitting a 2 nd order polynomial curve to the data of Powers et al., (1998) showing patellofemoral contact areas at varying levels of kf.

Patellofemoral contact pressure = patellofemoral contact force / contact area

Peak Achilles tendon force was determined by dividing the plantarflexion moment (MPF) by the estimated Achilles tendon moment arm (mat). This approach has been utilized previously to resolve differences in Achilles tendon force between different footwear and footstrike patterns (Kulmala et al., 2013) Sinclair, 2014). The moment arm was quantified as a function of the ankle sagittal plane angle (ak) using the procedure described by Self and Paine (2001):

$$
\begin{gathered}
\text { Achilles tendon force }=\text { MPF } / \text { mat } \\
\text { mat }=-0.5910+0.08297 a k-0.0002606 * a k^{2}
\end{gathered}
$$

Patellofemoral and Achilles tendon force were normalized by dividing the net values by body weight $(\mathrm{BW})$. Patellofemoral and Achilles tendon load rate $(\mathrm{BW} / \mathrm{s})$ were calculated as a function of the change in patellofemoral contact force from initial contact to peak force divided by the time to peak force. Patellofemoral and Achilles tendon instantaneous load rate $(\mathrm{BW} / \mathrm{s})$ were also determined as the peak increase in patellofemoral and Achilles tendon force between adjacent data points. 
From the force platform instantaneous loading rate was similarly normalized (BW/s) and calculated as the maximum increase in vertical force between adjacent data points. The acceleration signal was filtered with a $60 \mathrm{~Hz}$ low-pass Butterworth 4th order zero-lag filter (Sinclair et al., 2013). Peak tibial acceleration was defined as the highest positive acceleration peak measured during the stance phase. Tibial acceleration load rate was quantified by dividing the peak tibial acceleration magnitude by the duration over which the acceleration occurred. Finally, tibial acceleration instantaneous loading rate was calculated as the maximum increase in tibial acceleration between adjacent data points.

In addition, the effective mass (the proportion of body mass decelerated during the impact phase of stance) was also calculated. Effective mass was calculated in accordance with Liebermann et al., (2010) via the below equation. The vertical GRF integral pre transition was calculated using the integral of the vertical GRF between footstrike and impact peak, whereas post transition (where there was no impact peak) this was calculated over the same percentage of stance $(9.57 \pm 2.84 \%)$ (Liebermann et al., 2010).

Effective mass $=$ vertical GRF integral / vertical foot velocity at footstrike $+g$ * time to $9.57 \%$ stance

\section{Analysis}

Descriptive statistics of means, standard deviations and $95 \%$ confidence intervals were obtained for each outcome measurement. Shapiro-Wilk tests were used to screen the data for normality. The effects of the 10-week intervention on the 
biomechanical measurements were examined using paired t-tests with statistical significance was accepted at the $P \leq 0.05$ level (Sinclair et al., 2013). All statistical actions were conducted using SPSS v22.0 (SPSS Inc, Chicago, USA). In accordance with the recommendations of Roos \& Lohmander, (2013) and Salaffi et al., (2004) minimal perceptible clinical changes were considered to be 10 points on each of the KOOS subsections and 2 points on the NPS scale.

\section{Results}

Tables 2-5 present the perceived pain and biomechanical data obtained before and after the 10-week transition. The results showed that the intervention significantly influenced indices of perceived pain and also the biomechanical data.

KOOS and Achilles tendon pain scores

The NPS data revealed significant increases in perceived Achilles tendon pain (Table 2). Data from the KOOS survey showed significant reductions in 'pain', 'sport' and 'function and daily living' (Table 2). Importantly all of the significant alterations in perceived pain exceeded the threshold for minimal perceptible clinical change.

\section{Patellofemoral and Achilles tendon kinetics}

Significant reductions in peak patellofemoral contact force, peak patellofemoral contact pressure, patellofemoral instantaneous load rate and patellofemoral impulse were observed (Table 3; Figure 1ab). In addition, increases in peak Achilles tendon 
force, Achilles tendon load rate, Achilles tendon instantaneous load rate and Achilles tendon impulse were observed (Table 3; Figure 1c).

Tibial acceleration, loading rates and effective mass

Significant reductions in peak tibial acceleration, tibial acceleration load rate, tibial acceleration instantaneous load rate and instantaneous load rate were found (Table 4; Figure 2ab). In addition, a significant reduction in effective mass was also found (Table 4).

Joint kinematics

No differences in hip kinematics were evident (Table 5; Figure 3). A significant reduction in sagittal plane knee relative range of motion was shown (Table 5; Figure 3). In addition, at the ankle a significantly greater plantar flexion at footstrike was shown alongside a significant increase in sagittal plane relative range of motion (Table 5; Figure 3). At the ankle in the coronal plane a significantly larger degree of inversion at footstrike was shown alongside a significant increase in relative range of motion (Table 5; Figure 3).

\section{Discussion}

The aim of the current investigation was to examine the effects of a 10-week transition from a RF to FF strike pattern in runners with patellofemoral pain. To the authors knowledge this represents the first comparative investigation to examine the influence of a FF strike transition in runners with knee pain. Research of this nature may provide new information to recreational runners regarding the conservative management of patellofemoral pain. 
The first key finding from the current work is that the prescribed 10 footstrike transition program served to successfully alter the footstrike pattern of the runners. This is evidenced firstly by the significant alteration in ankle sagittal angle at footstrike following the 10-week intervention whereby all runners exhibited plantarflexion post transition. In addition, observation of the vertical GRF curve following the 10-week transition shows that the impact transient which was evident pre transition is no longer present following conversion to FF running. This protocol may therefore be used in future studies which seek to allow habitual RF runners to transition successfully to a FF pattern, although further work may be required to validate its effectiveness in running populations outside those examined in this investigation.

The current investigation tested the hypothesis that knee pain symptoms would be reduced as a function of the 10-week transition period. The findings from the current work support this proposition in that KOOS 'pain', 'sport' and 'function and daily living' aspects were significantly improved following the intervention. This observation provides support to the retrospective data of Daoud et al., (2012) which indicated that FF runners experience less chronic knee pathologies. The magnitudes of the improvements in pain were all shown to exceed the minimum values required for clinical relevance (Roos et al., 2013). This observation importantly indicates that converting to a FF running pattern has the potential to mediate clinically meaningful improvements in patient reported symptoms of patellofemoral pain in recreational runners. 
Of further clinical importance is that patellofemoral loading was also found to be significantly reduced following transition to FF strike running. This finding concurs with those of Kulmala et al., (2013) and Sinclair, (2014) who also showed that FF strike runners exhibited reduced patellofemoral kinetics in comparison to RF. The consensus regarding the development and initiation of patellofemoral pain symptoms in runners is that indicators develop as a function of excessive patellofemoral joint forces (Ho et al., 2012; La Bella et al., 2004). It is therefore proposed that the improvements in patellofemoral pain symptoms following the 10-week transition to FF running were at least in part mediated by the reductions in patellofemoral loading.

A further important finding from the current study is that tibial acceleration and loading rate parameters were also significantly attenuated as a function of the 10 week footstrike transition programme. It is proposed that this finding relates to the significant reduction in effective mass that was similarly noted following transition to FF running. In RF strike running the majority of the vertical momentum is absorbed by the collision as a greater proportion of body mass is decelerated during the impact phase (Liebermann et al., 2010). Whereas during FF running vertical momentum is converted into rotational momentum, thus the total mass being decelerated is reduced leading to a reduction in the magnitude of impact loading experienced by the body (Liebermann et al., 2010). This observation may also have clinical relevance as tibial accelerations and vertical rates of loading have been linked to the aetiology of numerous chronic running pathologies such as tibial stress fractures and plantar fasciitis (Milner et al., 2006; Pohl et al., 2009). 
In addition to reductions in patellofemoral pain symptoms, patellofemoral kinetics and impact loading, the 10 -week transition to FF running also mediated significant increases in perceived Achilles tendon pain and loads experienced by the Achilles tendon during the stance phase. This finding agrees with those of Kulmala et al., (2013) and Sinclair, (2014) who noted increases in Achilles tendon loads when running using a FF strike pattern. Similar to the data from the KOOS questionnaire the magnitude of the increase in perceived tendon pain was shown to exceed the minimal threshold considered to be clinically relevant (Salaffi et al., 2004). This finding indicates that converting to a FF running pattern does provide improvements patellofemoral pain symptoms, but that this may be at the expense of increased pain experienced by the Achilles tendon. Further research is needed to determine whether this pain persists or whether the Achilles tendon is able to adapt as the FF strike pattern becomes increasingly ingrained in the runner's motor program.

In conclusion, although previous analyses have investigated the biomechanical differences between RF and FF strike runners, there has yet to be any published research regarding the effects of transitioning from RF to FF striking in runners with patellofemoral pain. The current investigation therefore addresses this by providing a comparison of knee pain symptoms in RF strike runners with patellofemoral pain following a 10-week transition to FF running. The current study shows significant improvements in knee pain symptoms and significantly reductions in knee loading following the FF strike transition. However, the 10-week transition to FF running also mediated significant increases in Achilles tendon loading and perceived Achilles tendon pain. Therefore, the key implication from this study is that RF strike runners who suffer from patellofemoral pain can successfully transition to a FF running 
pattern and reduce their pain symptoms, however this may be at the expense of increased perceived pain at the Achilles tendon.

\section{Conflict of interest}

No conflict of interest will arise from publication of this manuscript.

\section{References}

1. Ahn AN, Brayton C, Bhatia T, Martin P. Muscle activity and kinematics of forefoot and rearfoot strike runners. J Sport Health Sci. 2014; 3: 102-112.

2. Besier TF, Gold GE, Beaupre GS, Delp SL. A modelling framework to estimate patellofemoral joint cartilage stress in vivo. Med Sci Sport Exerc. 2005; 37: 1924-1931.Taunton JE, Ryan MB, Clement DB, McKenzie DC, Lloyd-Smith DR, Zumbo, BD. A prospective study of running injuries: the Vancouver Sun Run “In Training” clinics. Br J Sports Med. 2013; 37: 239244.

3. Cappozzo A, Catani F, Leardini A, Benedeti MG, Della CU. Position and orientation in space of bones during movement: Anatomical frame definition and determination. Clin Biomech. 1995; 10: 171-178.

4. Cavanagh PR, Lafortune MA. Ground reaction forces in distance running. J Biomech. 1980; 13: 397-406.

5. Crossley $\mathrm{KM}$. Is patellofemoral osteoarthritis a common sequela of patellofemoral pain?. Br J Sports Med. 2014; 48: 409-410.

6. Crossley KM, Bennell KL, Green S, Cowan SM, McConnell J. Physical therapy for patellofemoral pain. A randomized, double-blinded, placebocontrolled trial. Am J Sports Med. 2002; 30: 857-865. 
7. Crowell HP, Davis IS. Gait retraining to reduce lower extremity loading in runners. Clin Biomech. 2011; 26: 78-83.

8. Divert C, Mornieux G, Freychat P, Baly L, Mayer F, Belli A. Barefoot-shod running differences: shoe or mass effect?. Int J Sport Med. 2008; 29: 512518.

9. Daoud AI, Geissler GJ, Wang F, Saretsky J, Daoud YA, Lieberman DE. Foot strike and injury rates in endurance runners: a retrospective study. Med Sci Sports Exerc. 2012; 44: 1325-34.

10. Graydon R, Fewtrell D, Atkins S, Sinclair, J. The test-retest reliability of different ankle joint center location techniques, FAOJ. 2015; Epub ahead of print.

11. Hamill J, Gruber AH, Derrick TR. Lower extremity joint stiffness characteristics during running with different footfall patterns. Eur J Sport Sci. $2014 ; 14: 130-136$.

12. Ho KY, Blanchette MG, Powers, CM. The influence of heel height on patellofemoral joint kinetics during walking. Gait Posture. 2012; 36: 271275.

13. Keino BJ, Powers CM. Patellofemoral stress during walking in persons with and without patellofemoral pain. Med Sci Sports Exerc. 2002; 34: 1582-1593.

14. Kulmala JP, Avela J, Pasanen K, Parkkari, J. Forefoot strikers exhibit lower running-induced knee loading than rearfoot strikers. Med Sci Sports Exerc.2013; 45: 2306-2313.

15. LaBella, C. Patellofemoral pain syndrome: evaluation and treatment. Prim Care.2004; 31: 977-1003. 
16. Lieberman DE, Venkadesan M, Werbel WA, Daoud AI, D'Andrea S, Davis IS, Mang'eni RO, Pitsiladis Y. Foot strike patterns and collision forces in habitually barefoot versus shod runners. Nature. 2010; 463: 531-535.

17. Milner CE, Ferber R, Pollard CD, Hamill J, Davis IS. Biomechanical factors associated with tibial stress fracture in female runners. Med Sci Sports Exerc. 2006; 38: 323.

18. Moore IS, Pitt W, Nunns M, Dixon, S. Effects of a seven-week minimalist footwear transition programme on footstrike modality, pressure variables and loading rates. Footwear Sci. 2015; 7: 17-29.

19. Nimon G, Murray D, Sandow, M, Goodfellow J. Natural history of anterior knee pain: a 14- to 20 -year follow up of nonoperative management. $\mathrm{J}$ Pediatr Orthop. 1998; 18: 118-122.

20. Pohl MB, Hamill J, Davis IS. Biomechanical and anatomic factors associated with a history of plantar fasciitis in female runners. Clin J Sport Med. 2009; 19: 372-376.

21. Powers CM, Lilley JC, Lee TQ. The effects of axial and multiplane loading of the extensor mechanism on the patellofemoral joint. Clin Biomech. 1998; 13: 616-624.

22. Roos EM, Lohmander LS. The Knee injury and Osteoarthritis Outcome Score (KOOS): from joint injury to osteoarthritis. Health Qual Life Outcomes. 2013; 1: 64.

23. Salaffi F, Stancati A, Silvestri CA, Ciapetti A, Grassi W. Minimal clinically important changes in chronic musculoskeletal pain intensity measured on a numerical rating scale. Eur Journal Pain. 2004; 8: 283-291. 
24. Self BP, Paine D. Ankle biomechanics during four landing techniques. Med Sci Sports Exerc. 2001; 33: 1338-1344.

25. Sinclair J, Bottoms L, Taylor K, Greenhalgh, A. Tibial shock measured during the fencing lunge: the influence of footwear. Sports Biomech. 2010; 9: $65-71$

26. Sinclair J, Taylor PJ, Hobbs SJ. Alpha level adjustments for multiple dependent variable analyses and their applicability-a review. Int $\mathrm{J}$ of Sports Sci Eng. 2013; 7: 17-20.

27. Sinclair J, Greenhalgh A, Brooks D, Edmundson CJ, Hobbs SJ. The influence of barefoot and barefoot-inspired footwear on the kinetics and kinematics of running in comparison to conventional running shoes. Footwear Sci. 2013; 5: 45-53.

28. Sinclair J, Taylor PJ, Currigan G, Hobbs SJ. The test-retest reliability of three different hip joint centre location techniques. Mov Sport Sci. 2014; 83: 31-39.

29. Sinclair J, Naemi R, Chockalingam N, Greenhalgh A. Investigation into the kinetics and kinematics during running in the heelless shoe. Footwear Sci. 2014; 6: 139-145.

30. Sinclair, J. Effects of barefoot and barefoot inspired footwear on knee and ankle loading during running. Clin Biomech. 2014; 29: 395-399.

31. Sinclair J, Hebron J, Taylor PJ. The Test-retest Reliability of Knee Joint Center Location Techniques. J App Biomech. 2015; 31: 117-121.

32. Squadrone R, Gallozzi C. Biomechanical and physiological comparison of barefoot and two shod conditions in experienced barefoot runners. J Sports Med \& Phys Fit. 2009; 49: 6-13. 
33. van Gent RN, Siem D, van Middelkoop M, van Os AG, Bierma-Zeinstra SMA, Koes BW. Incidence and determinants of lower extremity running injuries in long distance runners: a systematic review. $\mathrm{Br} \mathrm{J}$ Sports Med. 2007; 41: 469-480.

34. Warne JP, Kilduff SM, Gregan BC, Nevill AM, Moran KA, Warrington GD. A 4-week instructed minimalist running transition and gait-retraining changes plantar pressure and force. Scand J Med Sci Sport. 2014; 24: 964-973.

35. Williams DS, McClay IS, Manal KT. Lower extremity mechanics in runners with a converted forefoot strike pattern. J App Biomech. 2000; 16: 210 218.

36. Witvrouw E, Callaghan MJ, Stefanik JJ, Noehren B, Bazett-Jones DM, Willson JD, Earl-Boehm JE, Davis I, Powers CM, McConnell J, Crossley KM. Patellofemoral pain: consensus statement from the 3rd International Patellofemoral Pain Research Retreat held in Vancouver, September 2013. Br J Sports Med. 2014; 48: 411-414.

37. van Eijden TM, Kouwenhoven E, Verburg J, Weijs, WA. A mathematical model of the patellofemoral joint. J Biomech. 1986; 19: 219-229.

\section{Figures}

Figure 1: Mean patellofemoral and Achilles tendon kinetics pre and post transition ( $a .=$ patellofemoral force, b. $=$ patellofemoral pressure, $c .=$ Achilles tendon force $)$ (black $=$ pre transition $\&$ grey $=$ post transition $)$. 
Figure 2: Mean tibial acceleration and vertical GRF pre and post transition (a. = tibial acceleration, b. $=$ vertical GRF) (black $=$ pre transition $\&$ grey $=$ post transition).

Figure 3: Mean lower extremity kinematics pre and post transition (a. = sagittal plane, b. $=$ coronal plane, c. $=$ transverse plane $)($ black $=$ pre transition $\&$ grey $=$ post transition). 


\section{Dear Editor}

Please consider our paper "Effects of a 10 week footstrike transition in habitual rearfoot runners with patellofemoral pain" for consideration for publication in Comparative Exercise Physiology. We (the authors) feel that this is an important analysis as it highlights the clinical efficacy of transitioning from a rearfoot strike pattern in recreational runners with patellofemoral pain. The paper may aid our understanding of the biomechanical influence of altering running mechanics as a potential conservative intervention for recreational athletes who are susceptible to lower extremity pathologies. We hope this paper will stimulate further research and discussion through your publication. This manuscript has not been submitted anywhere else and will not be submitted anywhere else until a final decision from your journal is made. The research is original and unpublished previously. Each of the authors was fully involved in the study and preparation of the manuscript and has read and concurs with the content in the final document. There are no conflicts of interest for any of the authors of this publication.

I look forward to your review and comments of our work and sincerely hope that you enjoy reading.

Yours Sincerely

Dr Jonathan Sinclair

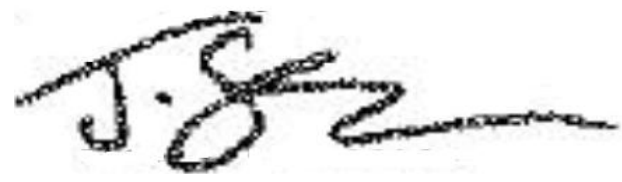



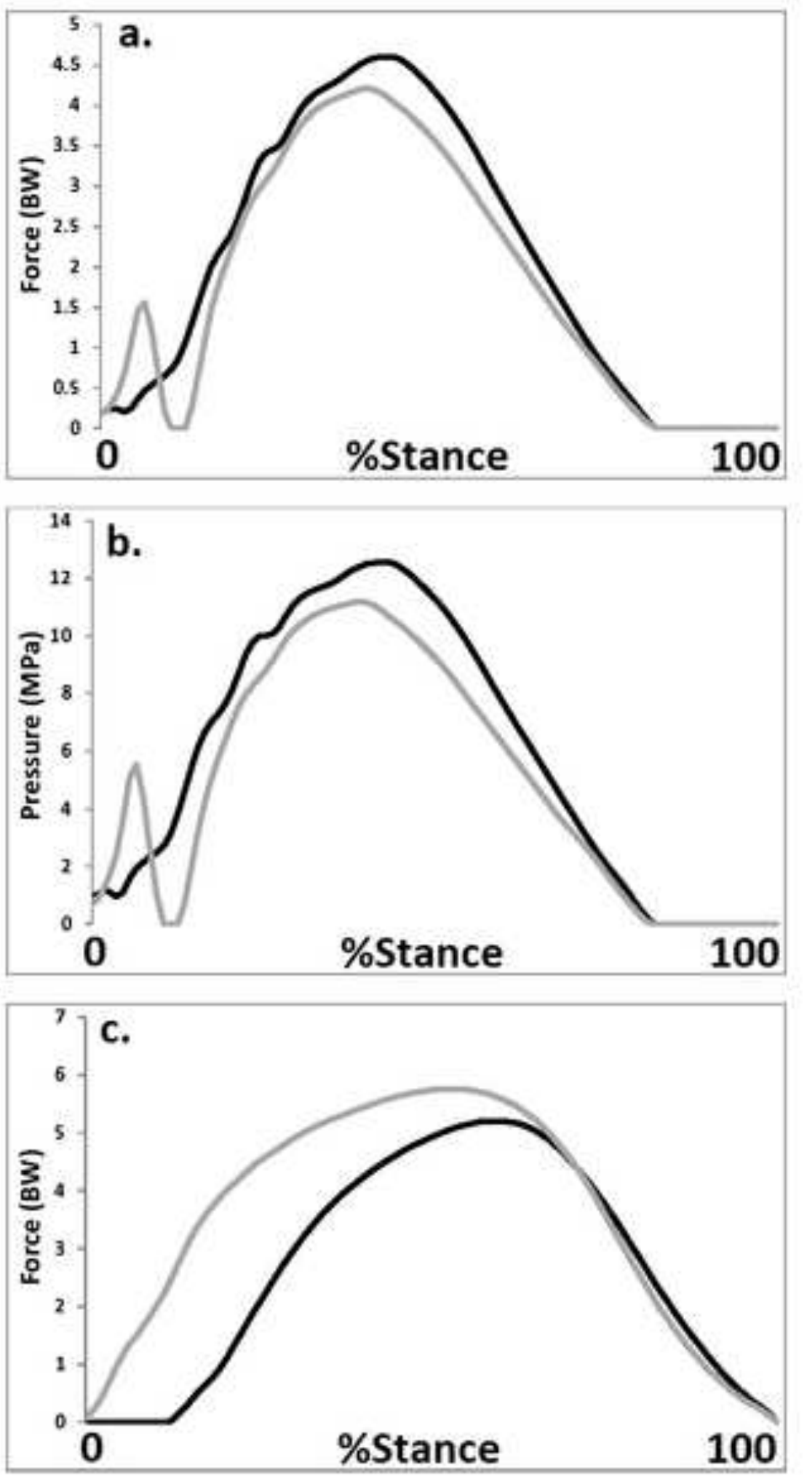

Figure
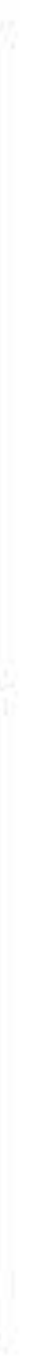

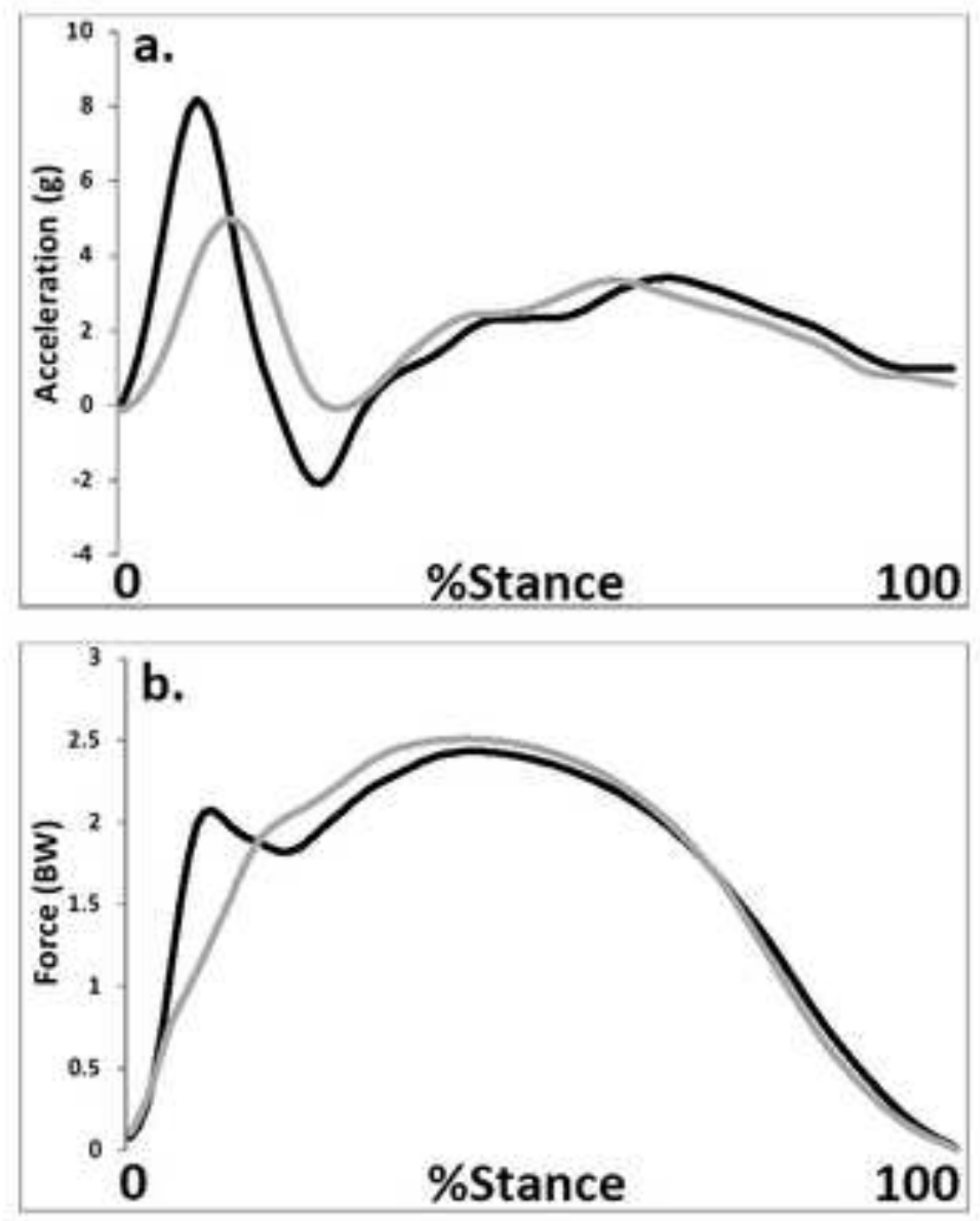

(10)


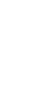
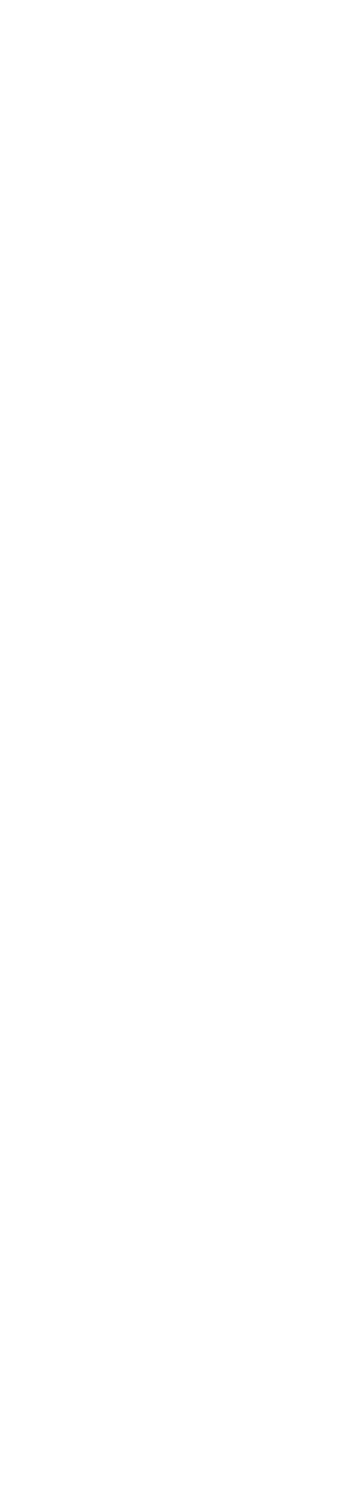
Hip
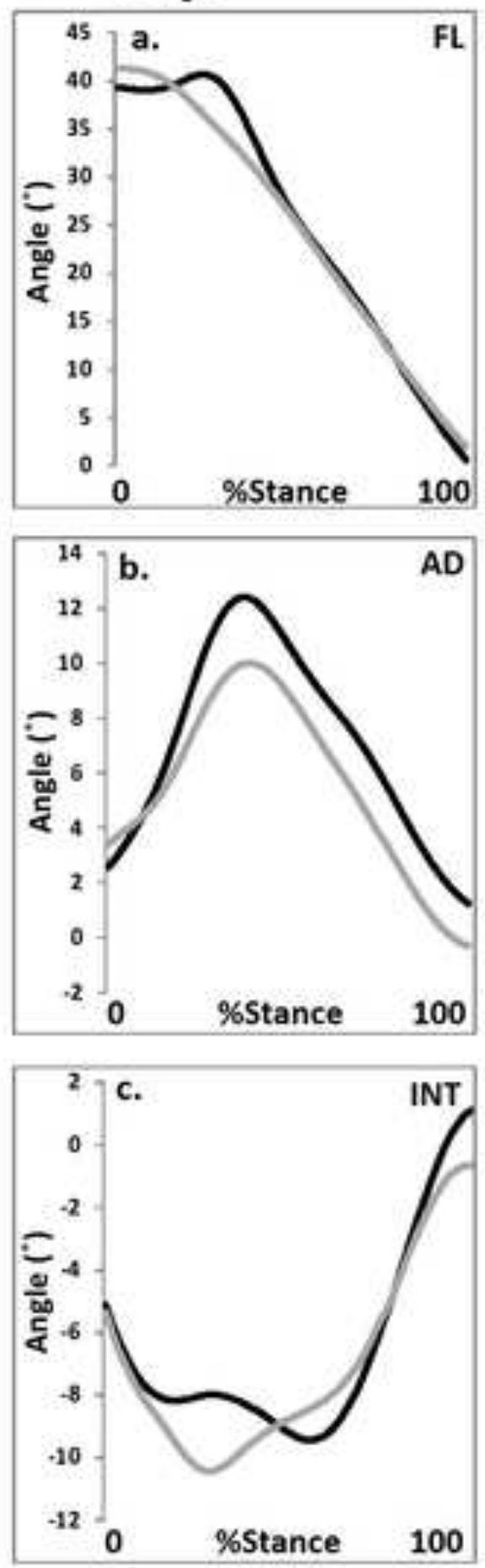

Knee
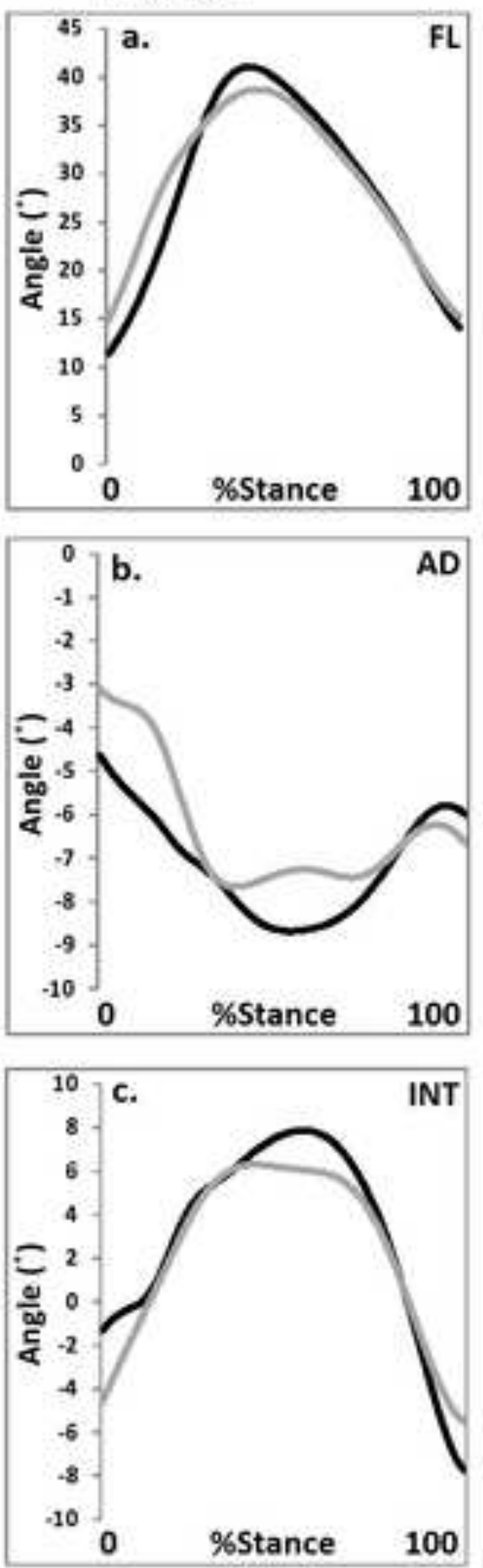

Ankle
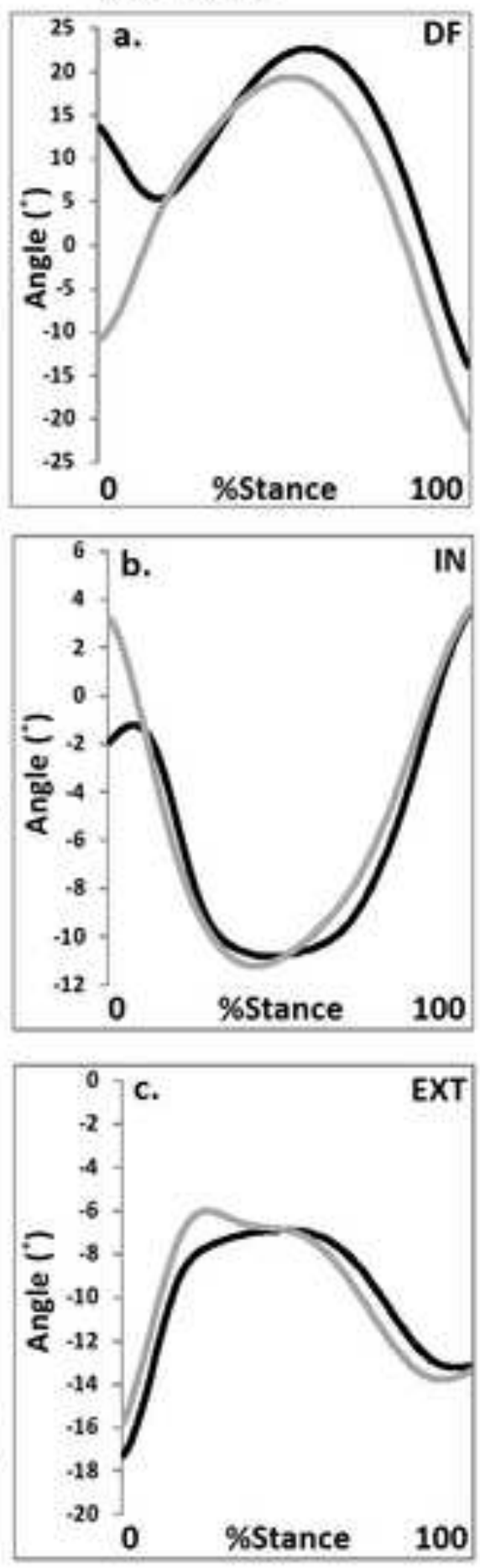
Table 1: Ten week transition program details.

\begin{tabular}{|c|c|c|c|c|c|c|c|c|c|}
\hline \multirow{3}{*}{ Week } & \multirow{3}{*}{$\begin{array}{c}\begin{array}{c}\text { Running } \\
\text { distance }\end{array} \\
\begin{array}{c}\text { Percent of } \\
\text { total mileage } \\
(\%)\end{array}\end{array}$} & \multicolumn{4}{|c|}{ Exercises } & \multicolumn{4}{|c|}{ Stretches } \\
\hline & & $\begin{array}{l}\text { Bilateral heel } \\
\text { raises }\end{array}$ & $\begin{array}{c}\text { Balance } \\
\text { diagonals }\end{array}$ & $\begin{array}{l}\text { Single leg } \\
\text { calf raise }\end{array}$ & $\begin{array}{c}\text { Single leg } \\
\text { balance } \\
\text { (60's) }\end{array}$ & $\begin{array}{l}\text { Wall Calf } \\
\text { Stretch }\end{array}$ & $\begin{array}{l}\text { Curb Calf } \\
\text { stretch }\end{array}$ & $\begin{array}{c}\text { Plantar } \\
\text { fascia } \\
\text { roll }\end{array}$ & Calf roll \\
\hline & & \multicolumn{4}{|c|}{ Sets/ repetitions (day) } & \multicolumn{2}{|c|}{ Hold for / repetitions } & \multicolumn{2}{|c|}{ Duration } \\
\hline 1 & 10 & $2 / 10$ & $2 / 10$ & $1 / 10$ & $1 / 1$ & $8 \mathrm{~s} / 2$ & $8 \mathrm{~s} / 2$ & $1 \mathrm{~min}$ & $1 \mathrm{~min}$ \\
\hline 2 & 20 & $2 / 10$ & $2 / 10$ & $1 / 10$ & $1 / 1$ & $8 \mathrm{~s} / 2$ & $8 \mathrm{~s} / 2$ & $1 \mathrm{~min}$ & $1 \mathrm{~min}$ \\
\hline 3 & 30 & $2 / 10$ & $2 / 10$ & $1 / 10$ & $1 / 1$ & $8 \mathrm{~s} / 3$ & $8 \mathrm{~s} / 3$ & $1 \mathrm{~min}$ & $1 \mathrm{~min}$ \\
\hline 4 & 40 & $3 / 10$ & $3 / 10$ & $2 / 12$ & $1 / 2$ & $8 \mathrm{~s} / 4$ & $8 \mathrm{~s} / 4$ & $2 \min$ & $2 \min$ \\
\hline 5 & 50 & $3 / 10$ & $3 / 12$ & $2 / 12$ & $1 / 2$ & $10 \mathrm{~s} / 4$ & $10 \mathrm{~s} / 4$ & $2 \min$ & $2 \min$ \\
\hline 6 & 60 & $3 / 12$ & $3 / 12$ & $3 / 12$ & $1 / 2$ & $15 \mathrm{~s} / 4$ & $15 \mathrm{~s} / 4$ & $2 \min$ & $2 \min$ \\
\hline 7 & 70 & $3 / 15$ & $3 / 12$ & $3 / 12$ & $2 / 2$ & $15 \mathrm{~s} / 4$ & $15 \mathrm{~s} / 4$ & $2 \min$ & $2 \min$ \\
\hline 8 & 80 & $3 / 15$ & $3 / 15$ & $3 / 15$ & $2 / 2$ & $15 \mathrm{~s} / 4$ & $15 \mathrm{~s} / 4$ & $2 \min$ & $2 \min$ \\
\hline 9 & 90 & $4 / 15$ & $4 / 15$ & $4 / 15$ & $2 / 3$ & $15 \mathrm{~s} / 5$ & $15 \mathrm{~s} / 5$ & $3 \min$ & $3 \min$ \\
\hline 10 & 100 & $5 / 15$ & $4 / 15$ & $4 / 15$ & $2 / 3$ & $15 \mathrm{~s} / 5$ & $15 \mathrm{~s} / 5$ & $3 \min$ & $3 \min$ \\
\hline
\end{tabular}


Table 2: Knee and Achilles tendon pain symptoms as a function of the footstrike transition intervention.

\begin{tabular}{|c|c|c|c|c|c|c|c|}
\cline { 2 - 8 } \multicolumn{1}{c|}{} & \multicolumn{3}{c|}{ Pre transition } & \multicolumn{3}{c|}{ Post transition } & \multirow{2}{*}{ P-value } \\
\cline { 2 - 8 } \multicolumn{1}{c|}{} & Mean & SD & $\mathbf{9 5 \%}$ CI & Mean & SD & $\mathbf{9 5 \%}$ CI & \\
\hline Achilles tendon NPS & 1.06 & 0.65 & $0.38-1.73$ & 2.67 & 0.88 & $1.75-3.59$ & 0.034 \\
\hline KOOS symptoms & 56.17 & 13.46 & $42.04-70.30$ & 63.05 & 19.05 & $43.06-83.03$ & 0.29 \\
\hline KOOS pain & 62.04 & 11.29 & $50.18-73.89$ & 78.41 & 13.81 & $63.91-92.90$ & 0.003 \\
\hline KOOS sport & 53.61 & 19.02 & $33.66-73.57$ & 72.67 & 15.07 & $56.85-88.48$ & 0.027 \\
\hline KOOS function and daily living & 67.68 & 12.54 & $54.53-80.84$ & 80.08 & 16.19 & $63.90-97.07$ & 0.001 \\
\hline KOOS quality of life & 56.13 & 18.70 & $29.50-68.75$ & 60.08 & 24.32 & $34.56-85.61$ & 0.115 \\
\hline
\end{tabular}

Notes $=$ For the KOOS subscales a greater value indicates lower pain 
Table 3: Patellofemoral and Achilles tendon kinetics as a function of the footstrike transition intervention.

\begin{tabular}{|c|c|c|c|c|c|c|c|}
\hline & \multicolumn{3}{|c|}{ Pre transition } & \multicolumn{3}{|c|}{ Post transition } & \multirow{2}{*}{ P-value } \\
\hline & Mean & $S D$ & $95 \% C I$ & Mean & $S D$ & $95 \% C I$ & \\
\hline Peak patellofemoral force (BW) & 4.76 & 1.29 & $3.68-5.83$ & 4.27 & 0.93 & $3.49-5.04$ & 0.025 \\
\hline Peak patellofemoral stress (MPa) & 13.10 & 3.05 & $10.55-15.65$ & 11.48 & 1.77 & $10.00-12.95$ & 0.035 \\
\hline Time to patellofemoral force (s) & 0.09 & 0.02 & $0.07-0.11$ & 0.09 & 0.03 & $0.06-0.11$ & 0.110 \\
\hline Patellofemoral load rate (BW/s) & 56.20 & 12.63 & $45.64-66.75$ & 53.76 & 12.31 & $43.47-64.06$ & 0.198 \\
\hline $\begin{array}{c}\text { Patellofemoral instantaneous load rate } \\
(\mathrm{BW} / \mathrm{s})\end{array}$ & 241.86 & 76.36 & $178.01-305.69$ & 156.84 & 35.79 & $126.91-186.76$ & 0.003 \\
\hline Patellofemoral impulse $(\mathrm{BW} \cdot \mathrm{s})$ & 0.45 & 0.17 & $0.31-0.59$ & 0.39 & 0.13 & $0.29-0.50$ & 0.111 \\
\hline Peak Achilles tendon force (BW) & 5.07 & 0.49 & $4.66-5.47$ & 5.58 & 0.77 & $4.93-6.23$ & 0.035 \\
\hline Time to peak Achilles tendon force (s) & 0.14 & 0.01 & $0.12-0.15$ & 0.13 & 0.03 & $0.11-0.15$ & 0.180 \\
\hline Achilles tendon load rate (BW/s) & 38.00 & 6.74 & $32.37-43.63$ & 46.62 & 12.62 & $36.07-57.17$ & 0.033 \\
\hline $\begin{array}{l}\text { Achilles tendon instantaneous load rate } \\
(\mathrm{BW} / \mathrm{s})\end{array}$ & 107.40 & 27.14 & $84.71-130.09$ & 134.34 & 43.55 & $97.93-170.75$ & 0.005 \\
\hline Achilles tendon impulse $(\mathrm{BW} \cdot \mathrm{s})$ & 0.57 & 0.06 & $0.52-0.62$ & 0.73 & 0.09 & $0.65-0.80$ & 0.001 \\
\hline
\end{tabular}


Table 4: Tibial acceleration and loading rate parameters as a function of the footstrike transition intervention.

\begin{tabular}{|c|c|c|c|c|c|c|c|}
\hline & \multicolumn{3}{|c|}{ Pre transition } & \multicolumn{3}{|c|}{ Post transition } & \multirow{2}{*}{$\begin{array}{c}\text { P- } \\
\text { value }\end{array}$} \\
\hline & Mean & $S D$ & $95 \% C I$ & Mean & $S D$ & $95 \% C I$ & \\
\hline Peak tibial acceleration (g) & 8.29 & 2.14 & $6.50-10.08$ & 5.33 & 0.51 & $4.90-5.76$ & 0.008 \\
\hline Time to peak tibial acceleration (s) & 0.02 & 0.01 & $0.01-0.03$ & 0.03 & 0.01 & $0.02-0.04$ & 0.117 \\
\hline Tibial acceleration load rate $(\mathrm{g} / \mathrm{s})$ & 399.89 & 163.89 & $262.87-536.91$ & 195.43 & 40.73 & $161.38-229.48$ & 0.007 \\
\hline $\begin{array}{l}\text { Tibial acceleration instantaneous load rate } \\
\qquad(\mathrm{g} / \mathrm{s})\end{array}$ & 536.12 & 191.06 & $376.39-695.85$ & 334.27 & 56.15 & $287.33-381.21$ & 0.020 \\
\hline Instantaneous load rate $(\mathrm{BW} / \mathrm{s})$ & 174.05 & 65.45 & $119.33-228.78$ & 102.62 & 13.22 & $91.57-113.68$ & 0.015 \\
\hline Effective mass (\%BW) & 7.39 & 2.41 & $5.16-9.62$ & 4.01 & 1.18 & $2.99-5.15$ & 0.001 \\
\hline
\end{tabular}


Table 5: Hip, knee and ankle joint kinematics as a function of the footstrike transition intervention.

\begin{tabular}{|c|c|c|c|c|c|c|c|c|}
\hline & \multicolumn{3}{|c|}{ Pre transition } & \multicolumn{3}{|c|}{ Post transition } & \multirow{2}{*}{ P-value } \\
\hline & & Mean & $S D$ & $95 \% C I$ & Mean & $S D$ & $95 \% C I$ & \\
\hline \multirow{12}{*}{$\stackrel{2}{a}$} & Sagittal plane & & & & & & & \\
\hline & Angle at footstrike $\left(^{\circ}\right)$ & 40.28 & 8.89 & $32.84-47.71$ & 39.68 & 9.76 & $31.52-47.84$ & 0.851 \\
\hline & Peak flexion $\left(^{\circ}\right)$ & 42.30 & 9.38 & $34.46-44.63$ & 40.26 & 9.46 & $32.35-48.17$ & 0.428 \\
\hline & Relative ROM $\left(^{\circ}\right)$ & 2.02 & 1.71 & $0.59-3.45$ & 0.58 & 0.97 & $-0.23-1.39$ & 0.107 \\
\hline & Coronal plane & & & & & & & \\
\hline & Angle at footstrike $\left(^{\circ}\right)$ & 2.71 & 5.97 & $-1.10-5.28$ & 3.62 & 4.48 & $-0.70-6.53$ & 0.262 \\
\hline & Peak adduction $\left({ }^{\circ}\right)$ & 11.86 & 2.25 & $9.98-13.75$ & 10.26 & 2.95 & $7.80-11.73$ & 0.092 \\
\hline & Relative ROM $\left(^{\circ}\right)$ & 9.24 & 2.85 & $6.85-11.62$ & 6.95 & 3.92 & $2.63-9.18$ & 0.061 \\
\hline & Transverse plane & & & & & & & \\
\hline & Angle at footstrike $\left(^{\circ}\right)$ & -5.69 & 6.47 & $34.46-44.63$ & -6.19 & 7.00 & $-12.04--0.34$ & 0.406 \\
\hline & Peak external rotation $\left({ }^{\circ}\right)$ & -10.81 & 5.11 & $-15.09--6.34$ & -11.35 & 5.69 & $-16.11--6.60$ & 0.275 \\
\hline & Relative ROM $\left(^{\circ}\right)$ & 5.12 & 3.34 & $2.23-7.91$ & 5.16 & 3.83 & $1.97-8.36$ & 0.910 \\
\hline \multirow{12}{*}{ 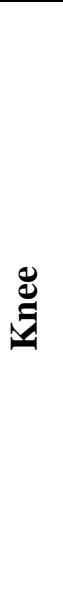 } & Sagittal plane & & & & & & & \\
\hline & Angle at footstrike $\left({ }^{\circ}\right)$ & 11.16 & 2.79 & $8.83-13.50$ & 13.63 & 6.17 & $8.47-18.80$ & 0.371 \\
\hline & Peak flexion $\left(^{\circ}\right)$ & 41.60 & 5.98 & $36.60-46.60$ & 39.50 & 9.03 & $31.95-47.05$ & 0.200 \\
\hline & Relative ROM $\left(^{\circ}\right)$ & 30.44 & 7.04 & $24.55-36.33$ & 25.87 & 6.54 & $20.41-31.33$ & 0.041 \\
\hline & Coronal plane & & & & & & & \\
\hline & Angle at footstrike $\left({ }^{\circ}\right)$ & -4.82 & 1.71 & $-6.25--3.39$ & -3.51 & 2.28 & $-4.41--0.60$ & 0.094 \\
\hline & Peak abduction $\left({ }^{\circ}\right)$ & -8.97 & 2.35 & $-10.94--7.00$ & -8.17 & 3.08 & $-10.74--5.99$ & 0.366 \\
\hline & Relative ROM $\left(^{\circ}\right)$ & 4.55 & 1.66 & $3.16-5.93$ & 5.66 & 1.90 & $4.07-7.25$ & 0.220 \\
\hline & Transverse plane & & & & & & & \\
\hline & Angle at footstrike $\left({ }^{\circ}\right)$ & -2.56 & 4.56 & $-6.38-1.25$ & -3.75 & 9.29 & $-9.52-6.02$ & 0.857 \\
\hline & Peak internal rotation $\left({ }^{\circ}\right)$ & 8.90 & 6.60 & $3.38-14.42$ & 8.35 & 9.94 & $0.04-16.66$ & 0.781 \\
\hline & Relative ROM $\left(^{\circ}\right)$ & 11.25 & 6.34 & $3.32-14.93$ & 11.10 & 7.25 & $4.04-16.17$ & 0.300 \\
\hline \multirow{12}{*}{$\frac{\frac{O}{x}}{E}$} & Sagittal plane & & & & & & & \\
\hline & Angle at footstrike $\left(^{\circ}\right)$ & 12.94 & 6.60 & $7.41-18.45$ & -8.66 & 9.29 & $-16.41-0.90$ & 0.001 \\
\hline & Peak dorsiflexion $\left(^{\circ}\right)$ & 22.44 & 2.95 & $19.98-24.90$ & 19.81 & 5.12 & $14.54-24.09$ & 0.128 \\
\hline & Relative ROM ( $\left.{ }^{\circ}\right)$ & 9.50 & 4.64 & $5.62-13.86$ & 28.47 & 6.33 & $23.18-33.77$ & 0.000 \\
\hline & Coronal plane & & & & & & & \\
\hline & Angle at footstrike $\left(^{\circ}\right)$ & -2.71 & 3.99 & $-6.04-0.63$ & 1.44 & 5.40 & $-3.07-5.96$ & 0.040 \\
\hline & Peak eversion $\left(^{\circ}\right)$ & -12.03 & 7.79 & $-18.54--5.52$ & -12.37 & 5.74 & $-17.17--7.58$ & 0.759 \\
\hline & Relative ROM $\left(^{\circ}\right)$ & 9.32 & 4.31 & $5.71-12.92$ & 13.82 & 6.14 & $8.68-18.95$ & 0.007 \\
\hline & Transverse plane & & & & & & & \\
\hline & Angle at footstrike $\left(^{\circ}\right)$ & -16.44 & 6.05 & $-21.50--11.39$ & -15.16 & 3.18 & $-17.81--12.50$ & 0.349 \\
\hline & Peak external rotation $\left({ }^{\circ}\right)$ & -7.29 & 3.41 & $-10.14--4.34$ & -6.47 & 3.25 & $-9.20--3.75$ & 0.155 \\
\hline & Relative ROM $\left(^{\circ}\right)$ & 9.67 & 4.25 & $6.12-13.21$ & 9.25 & 3.23 & $6.54-11.94$ & 0.646 \\
\hline
\end{tabular}

